\title{
A inserção da alta competição nos programas dos governos constitucionais em Portugal e o seu enquadramento normativo
}

\author{
Maria José Carvalho \\ Faculdade de Ciências do Desporto e de Educação Física \\ Universidade do Porto \\ Portugal
}

RESUMO

A alta competição, entendida como a prática desportiva inserida no âmbito do desporto de rendimento que corresponde à evidência de talentos e de vocações de mérito desportivo excepcional cujos resultados se aferem por padrões internacionais, carece de especial orientação e organização.

O propósito deste estudo foi investigar qual tem sido o espaço destinado a este subsistema desportivo nos programas dos catorze governos constitucionais em Portugal e pesquisar a intervenção do legislador quanto à regulamentação deste espaço de vida. Para tanto, procedemos à análise documental dos referidos programas governativos e à recolha e interpretação de todos os diplomas legais respeitantes à alta competição.

Os resultados obtidos evidenciaram que, à excepção dos V, VI, VII, todos os programas dos governos constitucionais incluem referências explícitas ou implícitas à alta competição com especial assento após o VIII Governo. O estudo revelou também que desde 1976 é consagrada à alta competição uma vasta produção legislativa, consubstanciada actualmente num conjunto de medidas de apoio específicas para atletas, treinadores, dirigentes e árbitros e na imposição de tarefas de organização próprias para as federações desportivas e a administração central.

Palavras-chave: Alta competição, Direito do Desporto, Legislação, Medidas de apoio à alta competição.

\begin{abstract}
The Insertion of Top-Level Competition in the Constitutional Governments' Programs of Portugal and its Legal Framework

Top-level competition, meaning the sportive practice within the scope of sport-performance, which corresponds to the appearance of talents and skills of exceptional merit whose results are assessed by international standards, lacks specific orientation and organisation.

In this study, we aim at investigating the space occupied by this sportive subsystem in the 14 constitutional governments' programs and studying the legislator's intervention in terms of regulating this sector of life. Therefore, we analysed those governments' programs and gathered all the legal diplomas related with top-level competition.

The results obtained lead us to consider that all but the V, VI, and VII constitutional governments' programs have explicit or implicit references to top-level competition, with a special emphasis after the VIII Government. The study also showed that specific laws have been published since 1976 focused on top-level competition, reinforced by a set of specific measures created to support athletes, coaches, officials and referees and by the obligation of fulfilling specific organisational tasks to sport federations and bodies of central administration.
\end{abstract}

Key Words: Top-level competition, Sport Law, Legislation, Supporting measures to Top-level competition. 


\section{INTRODUÇÃO}

A prática desportiva de alta competição, tanto na vertente profissional como na amadora, sobretudo pelo seu significado sociocultural e pela projecção da sua valência competitiva e espectacular, confere uma expressão ímpar ao fenómeno desportivo (7). É indubitável que, seja qual for a parte do globo em que nos fixemos, a alta competição das modalidades rainhas dessas culturas é, hoje em dia, para as populações, um espectáculo e uma manifestação cultural de grande atractividade.

Reflectir sobre a prática desportiva de alta competição é reflectir sobre um campo de expressão humana que pode ser perspectivado sob várias vertentes e matizes, e é iniludível que, do ponto de vista investigacional, todo este subsistema tem constituído nas últimas décadas um excelente campo de reflexão e estudo, quer pelas denominadas ciências sociais quer pelas ciências exactas (10). Também a Ciência do Direito através da produção legislativa, da doutrina e da jurisprudência tem, paulatinamente, vindo a intervir e a ser reclamada pelo desporto, e neste particular pela alta competição, no sentido de contribuir para a sua melhor organização e aperfeiçoamento. Tendo presente esta relação de intimidade entre o Direito e o Desporto, partimos para esta investigação formulando duas questões iniciais:

- Os programas dos catorze governos constitucionais consagram medidas específicas para a prática desportiva de alta competição?

- Qual a intervenção do legislador, após a Revolução de Abril de 1974, na regulamentação da prática desportiva de alta competição?

Assim, o objecto do presente trabalho assenta no estudo dos programas dos catorze governos constitucionais e de todos os diplomas respeitantes à alta competição publicados após a revolução de Abril de 1974, pelo que os campos de pesquisa incidem respectivamente nos Diários da Assembleia da República (DAR) e nos Diários da República (DR). Procedemos à análise de conteúdo e interpretação de tais instrumentos legislativos com o objectivo de averiguar a existência ou ausência de medidas programáticas relativas à alta competição nos documentos referidos, assim como investigar a produção nor- mativa respeitante a este subsistema desportivo e o seu enquadramento jurídico actual.

\section{A INSERÇÃO DA ALTA COMPETIÇÃO NOS PROGRAMAS DOS GOVERNOS CONSTITUCIONAIS}

Poder-se-á questionar a necessidade, ou não, de intervenção pública na normatização da alta competição, sendo ela já espaço de regulamentação nas estruturas associativas que a fomentam ${ }^{1}$. Porém, sendo o Direito um conjunto de regras de conduta social que regulam a convivência dos Homens em sociedade (8), facilmente se compreende que, dadas as tremendas exigências de rendimento físico-desportivo desta actividade, os seus crescentes interesses políticos e económicos e o elevado nível de atracção que adquiriu junto do grande público, se tenha tornado um espaço social a necessitar de um conjunto de normas gerais e abstractas para regular a sua existência e funcionamento. Estas normas emanam do ordenamento jurídico público, para que todos os operadores deste subsistema sejam usufrutuários em plena igualdade do mesmo estatuto, ou seja, adstritos aos mesmos direitos e obrigações. Caso contrário, seria um espaço de vida apenas ordenado pelos regulamentos federativos e, consequentemente, dependente das decisões e políticas eventualmente diferenciadas das várias modalidades, susceptíveis de criar desigualdades e assimetrias assinaláveis entre atletas que obtivessem resultados idênticos em representações internacionais de carácter similar. Devemos atender também à argumentação de Chaker (6) quando refere que Portugal, a par de outros países da Europa meridional e oriental, adoptou um modelo de legislação desportiva intervencionista. Ao percorrermos o nosso ordenamento jurídico desportivo verificamos que este intervencionismo remonta a 1942 com a emanação do histórico Decreto-Lei n. ${ }^{\circ} 32$ 241, de 5 de Setembro, relativo à organização da actividade desportiva. Nele subjaz uma intervenção plenamente dirigista, fruto da ideologia política do Estado Novo, diferente, naturalmente, da dos dias de hoje. Porém, mesmo após a

\footnotetext{
${ }^{1}$ Esta competência regulamentar deriva do disposto no artigo $21 .^{\circ}$, alínea h) do Decreto-Lei n. ${ }^{\circ} 144 / 93$, de 26 de Abril, que regula o regime jurídico das federações desportivas.
} 
transição do regime ditatorial para o regime democrático, o Estado Português não se inibiu de intervir legalmente no sistema desportivo.

Pensamos, pois, ser curial investigar se a alta competição tem sido considerada como matéria substantiva da actividade governamental na era após a Revolução de Abril de 1974. Para tal teremos, necessariamente, de analisar os programas dos catorze governos constitucionais, os quais constituem os documentos onde constarão as principais orientações políticas e medidas a adoptar no domínio deste subsistema desportivo. Da investigação efectuada aos programas mencionados deparamo-nos com três períodos distintos quanto ao seu conteúdo $(2,11)$ pelo que decidimos apresentar uma leitura desta intenção política agrupada em três momentos:

\section{A - do I ao IV governos constitucionais ${ }^{2}$}

Neste período, entre 1976 e 1978, época de grande instabilidade política com mudanças sucessivas de governos, a alta competição aparece com referências implícitas que se traduzem no apoio ao desporto federado (I e III GC), surge associada à execução de uma política de instalações desportivas que atenda às suas necessidades (II GC) e surge explicitamente no apoio a estudos na alta competição e definição de critérios de participação internacional (IV GC).

\section{B - do V ao VII governos constitucionais ${ }^{3}$}

Entre 1979 e 1981 os programas governativos não contemplaram, sequer implicitamente, a alta competição.

\section{C - do VIII ao XIV governos constitucionais ${ }^{4}$}

Após 1981, ultrapassada a fase de grande instabilidade política, a alta competição surge novamente como

${ }^{2}$ Publicados, respectivamente, nos DAR, II Série Suplemento ao n. ${ }^{\circ}$ 17, de 3 de Agosto de 1976; Suplemento ao n. ${ }^{\circ} 34$, de 3 de Fevereiro de 1978; n. ${ }^{\circ}$ 105, de 8 de Setembro de 1978 e n. ${ }^{\circ} 13$, de 5 de Dezembro de 1978.

${ }^{3}$ Publicados, respectivamente, nos DAR, II Série n. ${ }^{\circ} 96$, de 14 de Agosto de 1979, n. ${ }^{\circ} 11$, de 12 de Janeiro de 1980 e n. ${ }^{\circ}$ 20, de 17 de Janeiro de 1981.

${ }^{4}$ Publicados, respectivamente, nos DAR, II Série n. ${ }^{\circ} 101$, de 15 de Setembro de 1981; Suplemento ao n. ${ }^{\circ}$ 6, de 21 de Junho de $1993 ;$ n. $^{\circ} 4$, de 16 de Novembro de 1985; Suplemento ao n. ${ }^{\circ} 4$, de 28 de Agosto de 1987; II Série-C, n. ${ }^{\circ} 1$, de 15 de Novembro de 1991; II Série-A, n. ${ }^{\circ} 2$, de 8 de Novembro de 1995; II Série-A, n. ${ }^{\circ}$ 2, de 6 de Novembro de 1999. uma medida programática de carácter explícito traduzida nas seguintes menções:

a) Lançamento de um sistema de apoio à alta competição (VIII GC);

b) Incremento e consolidação do apoio aos atletas e equipas portuguesas, especialmente em Campeonatos da Europa, Campeonatos do Mundo e Jogos Olímpicos (IX, X, XI, XII, XIII e XIV GC);

c) Reestruturação da medicina desportiva, no sentido de permitir o desenvolvimento da investigação e apoio à alta competição ( XI e XIII GC);

d) Criação de estruturas de apoio específico, os centros de alto rendimento, que respondam às exigências de detecção, formação e acompanhamento dos praticantes de alta competição ( XIII GC) ;

e) Criação de condições para que as figuras de reconhecido prestígio do desporto português possam continuar a divulgar e a promover o desporto após o termo das suas carreiras desportivas (XIII GC).

Sintetizando, desde 1976 até aos dias de hoje, as principais medidas governativas ao nível da alta competição focalizam-se no sistema de apoio aos praticantes nas mais representativas competições internacionais, ao nível da medicina desportiva, na criação dos centros de alto rendimento e na constituição de modelos desportivos por parte dos praticantes de maior prestígio do desporto português. Fundamentalmente a partir de 1981, ou seja, do VIII Governo Constitucional, constatamos que a alta competição passou a figurar de forma explícita e contínua nos programas dos governos constitucionais.

\section{O ENQUADRAMENTO NORMATIVO DA ALTA COMPETIÇÃO}

Foram certamente feitos distintivos internacionais obtidos a partir de 1976 por atletas como Carlos Lopes ${ }^{5}$, Armando Marques, Rosa Mota, António Leitão, Aurora Cunha, Alexandre Yokochi, entre outros, e também, naturalmente, pressões de técnicos qualificados junto da administração central que

\footnotetext{
${ }^{5}$ Um primeiro marco assinalável é a vitória de Carlos Lopes no Campeonato do Mundo de Corta-Mato a 28 de Março de 1976.
} 
sensibilizaram a classe política e o legislador português para a realidade específica da alta competição e para as necessidades próprias destes atletas. Com efeito, até esta data reinava a improvisação e a anarquia neste sector da actividade desportiva (3). Da recolha por nós efectuada é também no ano de 1976 que descortinamos o primeiro normativo respeitante à alta competição, o Decreto-Lei n. ${ }^{\circ} 559 / 76,16$ de Julho de 1976. Este diploma consagrava normas relativas à requisição ou destacamento de trabalhadores dos sectores público ou privado para participarem em provas desportivas internacionais. Esta medida facilitou a participação dos nossos atletas nos Jogos Olímpicos de Montreal que decorreram de 17 de Julho a 1 de Agosto de 1976. Desde então, paulatinamente, começou a estruturar-se a edificação do regime jurídico da alta competição perfazendo até à presente data cerca de 50 diplomas com objectos de regulação diferenciados. Devemos deixar aqui expresso a importância da Portaria n. ${ }^{\circ} 730 / 80$, de 26 de Setembro, dado que constitui um marco substancial na valoração política e conceptual da alta competição. Neste diploma surge pela primeira vez o reconhecimento do desporto de alta competição como um elemento importante de desenvolvimento desportivo e é delineado o primeiro regulamento de apoio ao desporto de alto rendimento e o estatuto do atleta de alta competição. Ao longo de vinte anos vários diplomas revogaram e alteraram sucessivamente modelos organizativos e medidas de apoio aos agentes desportivos desta prática desportiva até ao aparecimento da Lei de Bases do Sistema Desportivo, a Lei n. ${ }^{\circ}$ 1/90, de 13 de Janeiro. Este foi, de facto, um momento de excelência no domínio da regulamentação do desporto na medida em que tal normativo estabeleceu as principais linhas político-jurídicas do sistema desportivo português. Esta lei geral do desporto consignou também, nas suas directrizes, a alta competição através de menção expressa no artigo $15 .^{\circ}$, o qual determinou ulterior regulamentação a fim de desenvolver cabalmente os princípios nele expressos e, diga-se em abono da verdade, que o legislador foi lesto a fazê-lo.

\footnotetext{
${ }^{6}$ Toda a legislação compilada desde esta data até aos dias de hoje pode ser consultada em Carvalho (2).
}

O primeiro decreto de desenvolvimento surge a 7 de Agosto de 1990 através do Decreto-Lei n. ${ }^{\circ}$ 257/90 e decorridos cinco anos ocorreu a sua revogação com o Decreto-Lei n. ${ }^{\circ}$ 125/95, de 31 de Maio. É este normativo que se mantém na actualidade com a alteração constante do Decreto-Lei n. ${ }^{\circ}$ 123/96, de 10 de Agosto. Contudo, existe um conjunto legislativo regulamentador de várias medidas de apoio ínsitas neste diploma que merecem destaque: Portaria n. ${ }^{\circ}$ 205/98, de 28 de Março, relativa às bolsas académicas a atletas de alta competição; Portaria n. ${ }^{\circ}$ 211/98, de 3 de Abril e Portaria n. ${ }^{\circ}$ 393/97, de 17 de Junho, respeitantes aos prémios, sendo a segunda destinada aos atletas deficientes; Portaria n. ${ }^{\circ}$ 947/95, de 1 de Agosto, que define os critérios técnicos para a qualificação como praticante desportivo de alta competição e praticante integrado no percurso de alta competição; Portaria n. ${ }^{\circ}$ 392/98, de 11 de Julho, relativa ao seguro desportivo especial dos praticantes em regime de alta competição e Decreto-Lei n. ${ }^{\circ}$ 393$\mathrm{A} / 99$, de 2 de Outubro, que regula os regimes especiais de acesso ao ensino superior permitindo aos atletas com estatuto e integrados no percurso de alta competição beneficiarem deste regime.

Atentemos, ao diploma que rege as medidas de apoio à alta competição, o Decreto-Lei n. ${ }^{\circ}$ 125/95, efectuando uma análise crítica dos seus principais aspectos caracterizadores $(2,12,13)$.

\subsection{Estrutura formal e material do diploma}

Trata-se de um diploma formalmente extenso, com 10 capítulos e 41 artigos, o qual revela sinais de sistematização algo defeituosa dado agrupar matérias com objectos diferenciados no mesmo capítulo, o que provoca alternâncias despropositadas de conteúdos. Veja-se o exemplo do Capítulo X, referente aos deveres dos praticantes, onde figuram os direitos dos cidadãos deficientes (artigo $40 .^{\circ}$ ) e os direitos dos seleccionáveis (artigo 39. ${ }^{\circ}$ ). Em termos materiais, destaque para a distinção na qualificação dos atletas em praticantes com estatuto de alta competição, praticantes integrados no percurso de alta competição, praticantes profissionais em regime de alta competição e praticantes que integram selecções nacionais. Estas diferentes qualificações implicam diferentes usufrutos das medidas de apoio consignadas no diploma, como veremos adiante. De assinalar 
também a extensibilidade do regime constante neste diploma a cidadãos deficientes que obtenham resultados de excelência na prática desportiva em competições internacionais.

Globalmente, a estrutura do normativo em análise é análoga à do Decreto-Lei n. ${ }^{\circ}$ 257/90, a qual resulta sobretudo de um trabalho de compilação de matérias relativas à alta competição que se encontravam reguladas em diplomas avulsos anteriores. Existe, por conseguinte, há mais de vinte anos, uma continuidade na filosofia subjacente à alta competição determinando que, para problemas novos, continuem a subsistir velhas soluções. Domínios relativos à regulação do estatuto social, com especial acuidade para o regime laboral e da segurança social, e do estatuto fiscal constituem lacunas assinaláveis na estrutura deste diploma e, consequentemente, fraquezas no tocante ao estatuto jurídico do praticante desportivo não profissional de alta competição.

\subsection{Conceito de alta competição}

Quando se fala em alta competição torna-se necessário enquadrar devidamente esta actividade, sem tibiezas quanto ao seu conceito. Juridicamente não surgem dúvidas de interpretação relativas ao conceito precipitado no artigo $2 .^{\circ}$ deste diploma: "a alta competição é a prática desportiva que, inserida no âmbito de desporto-rendimento, corresponde à evidência de talentos e de vocações de mérito desportivo excepcional, aferindo-se os resultados por padrões internacionais, sendo a respectiva carreira orientada para o êxito na ordem desportiva internacional". Facilmente se depreende que para integrar este conceito poderá não bastar ser campeão nacional, integrar a selecção nacional, ou ser um profissional do desporto prestigiado local ou nacionalmente, caso estes factos não se repercutam na obtenção de resultados internacionais suficientemente meritórios face aos padrões internacionais.

\subsection{Organização}

No que respeita à organização e desenvolvimento da prática desportiva de alta competição, são duas as organizações mencionadas no diploma em análise: uma do foro privado, as federações desportivas de utilidade pública desportiva, e outra do foro público, o Instituto do Desporto de Portugal.
Dadas as atribuições cometidas às federações desportivas, estas organizações conquistaram um espaço decisivo no fomento, planeamento e até regulamentação da alta competição das suas modalidades, restando praticamente à administração pública central a atribuição de meios financeiros aos programas por aquelas apresentados. Assim sendo, parece-nos importante a existência de uma terceira estrutura que perspective a prática desportiva de alta competição como um todo e, consequentemente, com competências de supervisão e orientação estratégica desta prática desportiva.

\subsection{Medidas de apoio a praticantes, treinadores, dirigentes e árbitros}

As medidas de apoio ínsitas no Decreto-Lei n. ${ }^{\circ}$ 125/95 têm diferentes destinatários: são eles os praticantes, os treinadores, os dirigentes e os árbitros, juízes, comissários e cronometristas.

\subsubsection{Quanto a praticantes}

Os atletas com estatuto de alta competição não profissionais podem beneficiar de medidas de apoio respeitantes aos seguintes domínios:

a) Regime escolar (artigos $9 .^{\circ}$ a $18 .^{\circ}$ );

b) Dispensa temporária de funções (artigos $19 .^{\circ} \mathrm{a}$ 21. ${ }^{\circ}$;

c) Obrigações militares (artigos $22 .^{\circ}$ e $23 .^{\circ}$ );

d) Acesso a formação superior, especializada e profissional (artigos $27 .^{\circ}$ a $29 . .^{\circ}$ );

e) Apoio material (artigos $30 .^{\circ}$ a $33 .{ }^{\circ}$ );

f) Seguro desportivo e apoio médico (artigos $34 .^{\circ} \mathrm{e}$ 35. ${ }^{\circ}$.

Deste conjunto de medidas exceptuam-se as bolsas de alta competição (artigo $30 .^{\circ}$ ) e o seguro desportivo especial (artigo $34 .^{\circ}$ ) para os praticantes integrados no percurso de alta competição e para os praticantes profissionais com estatuto de alta competição. Quanto aos atletas que, apesar de não integrarem a alta competição, participem regularmente nas selecções nacionais beneficiam de algumas medidas referentes ao regime escolar (artigos $100^{\circ}$ a $13 .^{\circ}$ ), à dispensa temporária de funções, às obrigações militares e apoio médico. 
Merecem-nos uma apreciação especial duas destas medidas, o regime escolar e o apoio material.

Actualmente, qualquer atleta estudante de alta competição terá um dia a dia deveras atribulado se pretender conciliar a sua actividade estudantil com a prática desportiva, na medida em que o tempo despendido em dois treinos diários e nas deslocações constitui, por si só, o horário normal de qualquer aluno que não seja praticante desportivo. Assim sendo, pensamos que medidas como a relevação de faltas, alteração de provas de avaliação, etc., pouco beneficiam os atletas de alta competição. É tempo de equacionar novas formas de enquadramento da vida destes praticantes desportivos. Quanto ao apoio material, os resultados de um estudo por nós realizado a atletas com estatuto de alta competição (2) indicaram que as bolsas de alta competição (art. ${ }^{\circ}$ $\left.30 .^{\circ}\right)$ não estavam a ser usufruídas por metade dos elementos da amostra, que apenas $14 \%$ dos elementos da amostra utilizavam centros especiais de apoio (art. ${ }^{\circ} 31 .^{\circ}$ ) para a sua preparação e que os prémios (art. ${ }^{\circ} 32 .^{\circ}$ ) atribuídos aos atletas lhes foram entregues ao fim de um prazo médio de nove meses. A pertinência destes resultados leva-nos a crer na necessidade dos responsáveis pela alta competição efectuarem constantes aferições entre o que está estipulado na lei e o que na realidade é usufruído pelos agentes aos quais ela se destina.

\subsubsection{Quanto a treinadores}

Os técnicos de apoio aos praticantes em regime de alta competição ou que acompanhem as selecções nacionais beneficiam das seguintes medidas:

a) Dispensa temporária de funções (artigos $19 .^{\circ}$ a 21..$^{\circ}$;

b) Regime escolar (artigo $11 .^{\circ}$ a $13 .^{\circ}$ );

c) Obrigações militares (artigos $22 .^{\circ}$ e $23 .^{\circ}$ );

d) Formação especializada (artigo 25..$^{\circ}$ );

e) Acesso ao ensino superior (artigo $27 .{ }^{\circ}$ );

f) Prémios (artigo $33 .^{\circ}$ ).

\subsubsection{Quanto a dirigentes}

Os dirigentes que se dediquem ao subsistema de alta competição ou que acompanhem as selecções nacionais beneficiam das necessárias adaptações do mencionado nas alíneas a), b) e c) respeitantes aos treinadores.
O legislador diferenciou os técnicos e dirigentes de apoio a praticantes em regime de alta competição daqueles técnicos e dirigentes que acompanhem selecções nacionais. Nada teríamos a contrapor caso não se vislumbrassem desigualdades assinaláveis na aplicação das medidas de apoio, com prejuízo para os treinadores de apoio aos atletas, como por exemplo não beneficiarem de medidas no domínio das obrigações militares, do horário escolar e regime de frequência e da relevação de faltas, o que traduz a confusão e incoerência reinantes neste domínio.

3.4.4. Quanto a árbitros, juízes, comissários e cronometristas Estes agentes podem beneficiar de relevação de faltas escolares, alteração de datas de provas de avaliação e dispensa temporária de funções aquando de deslocações a congressos ou eventos de nível internacional reconhecidos de interesse público.

O Decreto-Lei n. ${ }^{\circ}$ 125/95 consigna também deveres para os agentes desportivos da alta competição. Por conseguinte, os praticantes em regime de alta competição têm de se submeter regularmente aos controlos anti-dopagem, em competição ou fora dela (n. ${ }^{\circ} 1$ do artigo $36 .^{\circ}$ ) e integrar as selecções nacionais (n. 2 do artigo $36 .^{\circ}$ ). Também os treinadores e dirigentes devem zelar para que os praticantes sob seu acompanhamento se abstenham de qualquer forma de dopagem (artigo 38..$^{\circ}$.

\section{CONCLUSÕES}

Cumpre-nos neste espaço retirar as principais ilações do presente estudo e por conseguinte dar resposta às questões inicialmente formuladas. Assim, os resultados obtidos na investigação efectuada aos programas dos catorze governos constitucionais sugerem que $o$ apoio à alta competição constitui uma das medidas a adoptar no domínio da actividade governamental. Com excepção do V, VI, VII todos os governos constitucionais inserem a alta competição nos seus programas com especial incidência de continuidade a partir do VIII Governo Constitucional. Um segundo dado conclusivo, relativo à investigação da produção normativa respeitante a este subsistema desportivo, permite-nos afirmar que existe um vasto quadro normativo público fruto de um processo de apuramento legislativo desde 1976 até aos dias de hoje. O normativo referencial das medidas de apoio ao desen- 
volvimento deste subsistema desportivo, o Decreto-Lei n. ${ }^{\circ} 125 / 95$, de 31 de Maio, necessita de melhorias quer ao nível de técnica legislativa quer ao nível de reajustamentos à realidade hodierna dos agentes desportivos de alta competição.

\section{CORRESPONDÊNCIA}

\section{Maria José Carvalho}

Gabinete de Gestão Desportiva

Faculdade de Ciências do Desporto

e de Educação Física

Universidade do Porto

Rua Dr. Plácido Costa, 91

4200.450 Porto

mjc@fcdef.up.pt

\section{REFERÊNCIAS}

1. Berthelot, D.; Lamorlette, T.; Sablayrolles, R. (1989). Statut social et fiscal des athlètes de haut niveau. Paris: Editions Economica.

2. Carvalho, M.J. (2001). O apoio material à prática desportiva de alta competição: da Lei à realidade. Dissertação de Mestrado em Ciências do Desporto, na área de Especialização de Gestão Desportiva. FCDEF-UP. Edição do Instituto Nacional de Formação e Estudos do Desporto.

3. Carvalho, M. (1976). Desporto e Revolução. Uma política desportiva. Lisboa: DGD.

4. Castro, J.R. (1990). Lei de Bases do Sistema Desportivo Anotada e Comentada. Lisboa: Ministério da Educação.

5. Chabaud, L.; Dudognon C.; Primault D. (1993). Le Sportif et la Communauté Européenne. Le "statut social" du sportif de haut niveau. Paris : Editions Dalloz.

6. Chaker, A. N. (1999). Étude des législations nationales relatives au sport en Europe. Éditions du Conseil de l' Europe.

7. Lima, T. (1997). Significados sociais do desporto de alta competição. In: O desporto no século XXI: os novos desafios. Ed. Câmara Municipal de Oeiras, 73-77.

8. Machado, J.B. (1997). Introdução ao Direito e ao discurso legitimador. Coimbra: Almedina. 9. ${ }^{\mathrm{a}}$ Reimp.

9. Marivoet S.; Malveiro, O. (1999): As relações entre o Estado e o movimento associativo em Portugal (19841999). Revista Horizonte, 89: 25-32.

10. Marques, A. (1992). Os Jogos Olímpicos e a Ciência do Desporto. Revista Horizonte, 50: 61-66.

11. Meirim, J. M. (1994). Elementos para o estudo da política desportiva portuguesa. Revista Horizonte, 64: 123-129.

12. Meirim, J. M. (1997). O Enquadramento Jurídico do Desporto de Alta Competição. In: Actas do $2^{\circ}$ Congresso do Desporto da Confederação do Desporto de Portugal. Lisboa: Edição da CDP.

13. Pataco, V. (1997). Alta Competição em Portugal. Passado, Presente e Futuro. Revista Horizonte, 79: 3-10. 